\title{
Adrien de Monluc, Euvres. Euvres versifiées. Les Pensées du Solitaire. Les Jeux de l'Inconnu. Fables des amours du jour et de la nuit
}

\section{Daniela Dalla Valle}

\section{(2) OpenEdition \\ 1 Journals}

\section{Edizione digitale}

URL: http://journals.openedition.org/studifrancesi/8897

DOI: $10.4000 /$ studifrancesi.8897

ISSN: 2421-5856

\section{Editore}

Rosenberg \& Sellier

\section{Edizione cartacea}

Data di pubblicazione: 1 octobre 2008

Paginazione: 449

ISSN: 0039-2944

\section{Notizia bibliografica digitale}

Daniela Dalla Valle, «Adrien de Monluc, Euvres. E Euvres versifiées. Les Pensées du Solitaire. Les Jeux de I'Inconnu. Fables des amours du jour et de la nuit», Studi Francesi [Online], 155 (LII | II) | 2008, online dal 30 novembre 2015, consultato il 13 janvier 2021. URL: http://journals.openedition.org/studifrancesi/ 8897 ; DOI: https://doi.org/10.4000/studifrancesi.8897

Questo documento è stato generato automaticamente il 13 janvier 2021.

\section{cc) $($ ) $\ominus$}

Studi Francesi è distribuita con Licenza Creative Commons Attribuzione - Non commerciale - Non opere derivate 4.0 Internazionale. 


\title{
Adrien de Monluc, CEuvres. Euvres versifiées. Les Pensées du Solitaire. Les Jeux de l'Inconnu. Fables des amours du jour et de la nuit
}

\author{
Daniela Dalla Valle
}

\section{NOTIZIA}

ADRIEN DE MONLUC, CEuvres. CEuvres versifiées. Les Pensées du Solitaire. Les Jeux de l'Inconnu. Fables des amours du jour et de la nuit, éd. Michael KRAMER, étude historique-biographique V. GARRIGUES, Paris, Champion, 2007, pp. 906.

1 Adrien de Monluc, conte di Carmain - o di Carmail, o di Cramail - è il dedicatario della

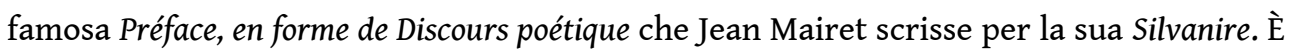
stato un personaggio famoso, collegato al libertinaggio, a Vanini, autore di opere quasi mai firmate e quindi - come scrittore - piuttosto misterioso. Questo imponente volume di Champion si propone di indagare sulla sua personalità, ma anche sulla sua produzione, di cui fa una lista cronologica e di cui fornisce l'edizione.

2 In una lunga parte introduttiva, véronique GARRIGUES - già autrice della prima biografia scientifica di Adrien de Monluc (2006) - propone uno studio storico-biografico molto accurato, che accompagna Monluc nella sua patria guascone, con i suoi amori e il suo matrimonio; poi a corte, sottolineando i suoi contatti con Enrico IV, il rapporto con i problemi religiosi, infine la sua presenza in alcune missioni diplomatiche. Segue un'introduzione intitolata Solitaire et inconnu, di Michael KRAMER (già editore, nel 2003, della Comédie de proverbes, testo da alcuni attribuito ad Adrien de Monluc), che cerca di andare più a fondo nell'analisi del personaggio, presentato come un "dévot libertin", e della produzione letteraria che gli è attribuita. M. Kraemer definisce questo suo studio come «un déblayage de terrain pour des recherches à venir». 
3 Poi le varie opere, quasi tutte in prosa - lettere, Pensées -, sono pubblicate, analizzate e sottoposte a una ricerca puntuale, destinata a fissare la loro datazione e anche la loro effettiva attribuzione all'autore. Ogni opera è corredata da una Notice e da una serie di note. 